STRUCTURAL BIOLOGY COMMUNICATIONS

ISSN 2053-230X
Received 1 June 2016

Accepted 13 July 2016

Edited by M. S. Weiss, Helmholtz-Zentrum Berlin für Materialien und Energie, Germany

Keywords: siderophore-interacting protein; Shewanella frigidimarina; crystallographic analysis.

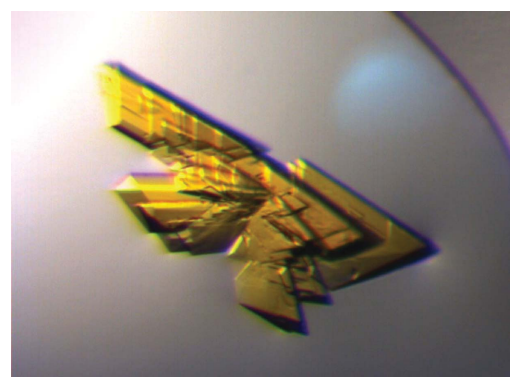

OPEN $\odot$ ACCESS

\section{A putative siderophore-interacting protein from the marine bacterium Shewanella frigidimarina NCIMB 400: cloning, expression, purification, crystallization and X-ray diffraction analysis}

\author{
Inês B. Trindade, ${ }^{a}$ Bruno M. Fonseca, ${ }^{a}$ Pedro M. Matias, ${ }^{a, b}$ Ricardo O. Louro ${ }^{a}$ and
} Elin Moe $^{\mathrm{a} *}$

anstituto de Tecnologia Química e Biológica António Xavier, Universidade Nova de Lisboa, Avenida da República (EAN), 2780-157 Oeiras, Portugal, and ${ }^{\mathbf{b}}$ Instituto de Biologia Experimental e Tecnológica (iBET), Apartado 12, 2780-901 Oeiras, Portugal. *Correspondence e-mail: elinmoe@itqb.unl.pt

Siderophore-binding proteins (SIPs) perform a key role in iron acquisition in multiple organisms. In the genome of the marine bacterium Shewanella frigidimarina NCIMB 400, the gene tagged as SFRI_RS12295 encodes a protein from this family. Here, the cloning, expression, purification and crystallization of this protein are reported, together with its preliminary X-ray crystallographic analysis to $1.35 \AA$ resolution. The SIP crystals belonged to the monoclinic space group $P 2_{1}$, with unit-cell parameters $a=48.04, b=78.31, c=67.71 \AA, \alpha=90$, $\beta=99.94, \gamma=90^{\circ}$, and are predicted to contain two molecules per asymmetric unit. Structure determination by molecular replacement and the use of previously determined $\sim 2 \AA$ resolution SIP structures with $\sim 30 \%$ sequence identity as templates are ongoing.

\section{Introduction}

The Great Oxygenation Event (GOE) was marked by a profound transition in ocean chemistry, where the previously readily available iron became a limiting nutrient worth battling for (Holland, 2006). In an oxygen-rich atmosphere, two redox states of iron are accessible to biology: an oxidized, insoluble ferric state, iron(III), and a highly reactive reduced ferrous state, iron(II). The reversibility of this redox pair, iron(II)/iron(III), plays a crucial role in several metabolic processes including the electron-transport chain, photosynthesis, oxidative phosphorylation and the tricarboxylic acid cycle (Miethke \& Marahiel, 2007).

To circumvent low iron bioavailability, organisms have found diverse strategies for importing and utilizing iron, including direct extracellular reduction (Deneer et al., 1995), the acquisition of iron-bound or haem proteins using specific receptors (Wandersman \& Delepelaire, 2004) and the synthesis and extracellular release of small molecules with high affinity for ferric iron named siderophores (Neilands, 1981).

These iron siderophores are strong ferric chelators and can be used in various applications, including the cultivation of uncultured microorganisms, as ecofriendly substitutes for pesticides, as enhancers in the bioremediation of heavy metals, in iron-overload therapy, in cancer therapy and as Trojan horse antibiotics (Saha et al., 2016).

Given their vast applications, considerable efforts have been made in research to understand the mechanistic details behind siderophore synthesis, transport and regulation (Miethke et al., 2011; Schalk \& Guillon, 2013; Crosa \& Walsh, 
Table 1

Macromolecule-production information.

\begin{tabular}{ll}
\hline Source organism & S. frigidimarina NCIMB 400 \\
DNA source & S. frigidimarina NCIMB 400 \\
Forward primer $\left(5^{\prime}-3^{\prime}\right)$ & ATG AAT AAC CAA TCA GCT AAA AAA TCT \\
& CC \\
Reverse primer $\left(5^{\prime}-3^{\prime}\right)$ & CTA CAA CGG CTG CAT CTG CTT TTG \\
Cloning vector & pETBlue-1 (Novagen) \\
Expression vector & pETBlue-1 (Novagen) \\
Expression host & E. coli Tuner (DE3) pLacI \\
Complete amino-acid sequence & MNNQSAKKSPTRLTYISDIIEISPYLRRLVLSGE- \\
of the construct produced & QLANFPADQQGAYVKVIPQPGETTVNMTLTG- \\
& PNAAIKRSYTIREFDPVRGLSLDFVINKHTG- \\
& PATDWAKLANVGDTVAIAGPGPLKMNRFDFND- \\
& YLLFGDSTSINAVDALIKRLPATAKGHIIMLV- \\
& NSHQEQALLSQHPLLKTHWLVLNDSITAEQQI- \\
& DWLLDKLELFGDLPAVTQVFVGLEATQVRVIK- \\
& QYLLEQQQLPLSSISATGYWKRNTDADTFGKQ- \\
& KQMQPL
\end{tabular}

Theoretical pI 7.6

$\dagger$ Calculated using Protein Calculator (http://protcalc.sourceforge.net/).

2002). At the molecular level, one of the least explored aspects of siderophore use is the release of the imported iron from ferric siderophore complexes. In order to be utilized, iron needs to be released from these high-affinity complexes. Two strategies have been reported so far. One is the release of iron through hydrolytic cleavage of the siderophore complex by esterases (Brickman \& McIntosh, 1992). The other is singleelectron reduction, also known as siderophore recycling, which is either mediated by unspecific endogenous reducing agents (Brickman \& McIntosh, 1992) or by specific siderophore ferric reductases (Miethke et al., 2011).

In 2015, $\mathrm{Li}$ and coworkers suggested that two families of specific siderophore reductases exist. One is the FADcontaining siderophore-interacting protein (SIP) family and the other is the ferric siderophore reductase (FSR) protein family, which contains an iron-sulfur cluster as a redox centre (Li et al., 2015). Several members of the SIP family have been characterized [for example, ViuB from Vibrio cholerae (Butterton \& Calderwood, 1994), IrtA from Mycobacterium tuberculosis (Ryndak et al., 2010), YqjH from Escherichia coli (Miethke et al., 2011) and FscN from Thermobifida fusca (Li et al., 2015)]. Presently, catalytic mechanisms have been proposed for the SIP family, namely for its members YqjH and FscN. Both of these proteins indicate a preference for NADPH as a reducing agent, although $\mathrm{Yqj} H$ is able to reduce various iron chelates, whereas $\mathrm{FscN}$ is only able to reduce the endogenous siderophore fuscachelin (Miethke et al., 2011; Li et al., 2015). Two structures of SIPs have been deposited in the PDB: the $1.89 \AA$ resolution structure of FscN from the Gram-positive T. fusca (PDB entry 4yhb; Li et al., 2015) and the $2.2 \AA$ resolution structure of a SIP from the Gram-negative bacterium Shewanella putrefaciens (PDB entry 2gpj; Joint Center for Structural Genomics, unpublished work). Here, we report the cloning, expression, purification and crystallization of a SIP from the marine bacterium $S$. frigidimarina NCIMB 400. Further knowledge of the mechanistic and structural details of this family of proteins, namely with respect to the ligand-binding pockets, may provide new strategies for controlling the performance of siderophore recycling and utilization. This knowledge is relevant for the development of new drugs that inhibit the growth and virulence of pathogens and also for promoting a more efficient use of siderophores in bioremediation via the protein engineering of SIPs.

\section{Materials and methods}

\subsection{Macromolecule production}

The SFRI_RS12295 gene fragment was amplified via polymerase chain reaction (PCR) from the genomic DNA of S. frigidimarina NCIMB 400 using the primers listed in Table 1. The PCR product was ligated into the expression vector pETBlue-1 (Novagen) and transformed into competent E. coli Tuner (DE3) pLacI cells for expression. Protein overexpression was achieved using an autoinduction method (Blommel et al., 2007; Studier, 2005). The cells were first grown overnight in Luria-Bertani (LB) medium supplemented with $35 \mathrm{mg} \mathrm{l}^{-1}$ chloramphenicol and $100 \mathrm{mg} \mathrm{l}^{-1}$ ampicillin at $30^{\circ} \mathrm{C}$

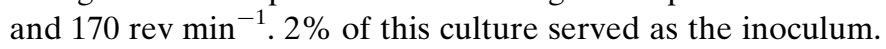
The auto-induction medium was made by adding $50 \mathrm{ml} 20 \times$ NPS stock solution $\left[1 M \mathrm{Na}_{2} \mathrm{HPO}_{4}, 1 M \mathrm{KH}_{2} \mathrm{PO}_{4}, 500 \mathrm{mM}\right.$ $\left.\left(\mathrm{NH}_{4}\right)_{2} \mathrm{SO}_{4}\right]$ and $20 \mathrm{ml} 50 \times 5052$ stock solution consisting of $25 \%(w / v)$ glycerol, $2.5 \%(w / v)$ glucose, $10 \%(w / v) \alpha$-lactose monohydrate to $11 \mathrm{LB}$ medium supplemented with $1 \mathrm{mM}$ $\mathrm{MgSO}_{4}, 35 \mathrm{mg} \mathrm{l}^{-1}$ chloramphenicol and $100 \mathrm{mg} \mathrm{l}^{-1}$ ampicillin (Blommel et al., 2007; Studier, 2005). The cells were allowed to grow continuously for $30 \mathrm{~h}$ at $30^{\circ} \mathrm{C}$ and $170 \mathrm{rev} \mathrm{min}{ }^{-1}$.

Cells were harvested by centrifugation for $10 \mathrm{~min}$ at $11305 \mathrm{~g}$ and were then cooled to $-80^{\circ} \mathrm{C}$. The cells were later defrosted and resuspended in $20 \mathrm{~m} M$ Tris- $\mathrm{HCl}$ buffer $\mathrm{pH} 7.6$ with a protease-inhibitor cocktail (Roche) and DNase I (Sigma) prior to a three-pass cell disruption at $6.9 \mathrm{MPa}$ using a French press. The lysate was centrifuged at $11305 \mathrm{~g}$ to remove undisrupted cells and then ultracentrifuged at $204709 \mathrm{~g}$ for $90 \mathrm{~min}$ at $4^{\circ} \mathrm{C}$ to remove cell membranes and debris. The supernatant was dialyzed overnight against $20 \mathrm{mM}$ Tris- $\mathrm{HCl}$ buffer $\mathrm{pH} 7.6$ and concentrated using an Amicon Ultra Centrifugal Filter (Millipore) with a $10 \mathrm{kDa}$ cutoff. The SIP was purified from the supernatant using two ion-exchange chromatography columns: a Q Sepharose Fast Flow column (GE Healthcare) followed by an SP Sepharose Fast Flow column (GE Healthcare). Both columns had previously been equilibrated with $20 \mathrm{~m} M$ Tris- $\mathrm{HCl}$ buffer $\mathrm{pH} 7.6$ and were used with a stepwise elution method. The fraction containing the SIP eluted from the Q Sepharose column at $150 \mathrm{mM} \mathrm{NaCl}$. This fraction was dialyzed against $20 \mathrm{~m} M$ Tris- $\mathrm{HCl}$ buffer $\mathrm{pH}$ 7.6, concentrated and loaded onto the SP Sepharose column. The fraction containing the SIP was eluted at $100 \mathrm{mM} \mathrm{NaCl}$.

Eluted fractions were analysed by SDS-PAGE with BlueSafe staining (NZYTech) and UV-visible spectroscopy to select fractions containing the purified SIP.

\subsection{Crystallization}

Purified protein $\left(30 \mathrm{mg} \mathrm{ml}^{-1}\right)$ in $20 \mathrm{mM}$ Tris- $\mathrm{HCl} \mathrm{pH} \mathrm{7.6,}$ $150 \mathrm{~m} M \mathrm{NaCl}$ was diluted to $10 \mathrm{mg} \mathrm{ml}^{-1}$ with $20 \mathrm{~m} M$ Tris- $\mathrm{HCl}$ $\mathrm{pH} 7.6$ (final salt concentration $50 \mathrm{mM} \mathrm{NaCl}$ ) and used for 
crystallization experiments on a Honeybee Cartesian crystallization robot (Genomic Systems) with MDL3 plates (100 nl protein solution and $40 \mu \mathrm{l}$ reservoir solution) and the JCSGplus crystallization screen (Molecular Dimensions). Yellow crystals appeared in 12 out of 96 crystallization conditions. The most promising crystals were found in well A5 with the following reservoir solution: $20 \%$ PEG 3350, $0.2 \mathrm{M}$ magnesium formate dihydrate. In an attempt to improve the crystal size, hanging-drop optimization experiments were performed by hand, varying the concentration of PEG 3350 from 18 to $22 \%(w / v)$ and of magnesium formate dihydrate from 0.18 to $0.22 M$. Crystals appeared in all conditions after $1 \mathrm{~d}$ and were fully grown after $3 \mathrm{~d}$. In order to confirm that the crystals obtained consist of the SIP, crystals were collected from some of the drops, washed twice in reservoir solution and analysed by SDS-PAGE. The crystallization conditions for the crystal used for data collection are described in Table 2.

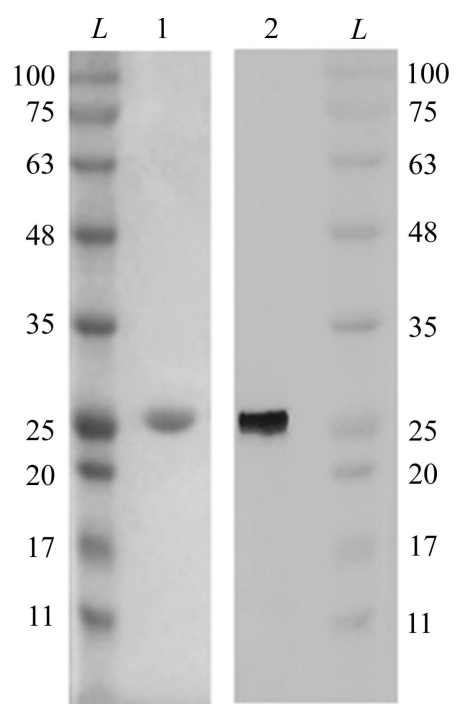

(a)

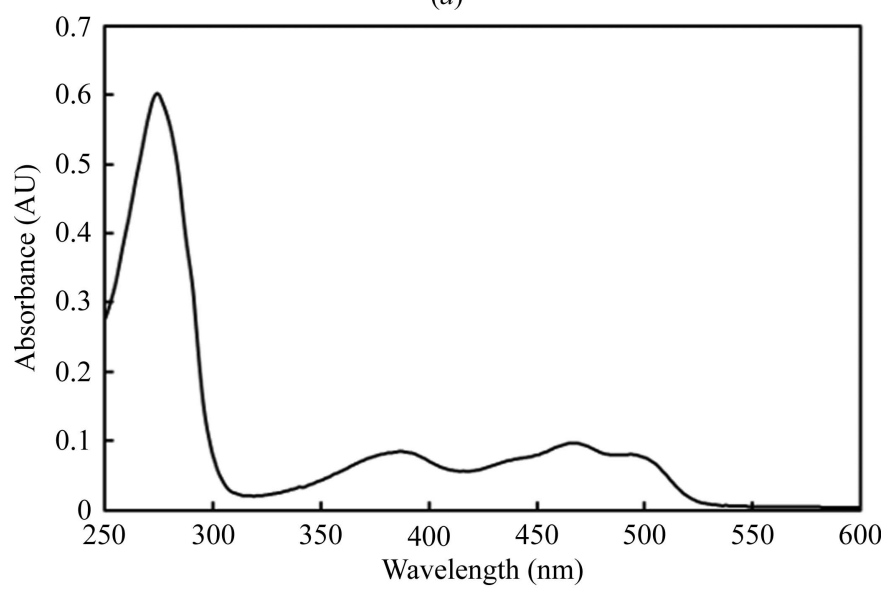

(b)

Figure 1

(a) $12 \%$ SDS-PAGE gels. Lanes 1 and 2 correspond to the purified SIP fraction before crystallization and dissolved multiple crystals of the SIP, respectively. Lane $L$ corresponds to the protein ladder (labelled in $\mathrm{kDa}$ ). (b) UV-visible profile of the purified protein. The UV-visible spectrum was measured in a Shimadzu UV-1800 UV-Vis spectrophotometer using a fast scan rate.
Table 2

Crystallization conditions.

\begin{tabular}{ll}
\hline Method & Hanging drop \\
Plate type & EasyXtal 15-Well Tool (Qiagen) \\
Temperature $\left({ }^{\circ} \mathrm{C}\right)$ & 18 \\
Protein concentration $\left(\mathrm{mg} \mathrm{ml}^{-1}\right)$ & 10 \\
Buffer composition of protein & $20 \mathrm{~m} M$ Tris-HCl pH 7.6, $50 \mathrm{~m} M \mathrm{NaCl}$ \\
$\quad$ solution & \\
Composition of reservoir solution & $22 \%$ PEG 3350, 0.22 $M$ magnesium \\
& formate dihydrate \\
Volume and ratio of drop & $2 \mu \mathrm{l}, 1: 1$ \\
Volume of reservoir $(\mu \mathrm{l})$ & 500 \\
\hline
\end{tabular}

Table 3

Data collection and processing.

\begin{tabular}{ll}
\hline Diffraction source & Beamline I04, DLS \\
Wavelength $(\AA)$ & 0.9795 \\
Temperature $(\mathrm{K})$ & 100 \\
Detector & Pilatus 6M-F \\
Rotation range per image $\left({ }^{\circ}\right)$ & 0.10 \\
Total rotation range $\left({ }^{\circ}\right)$ & 180 \\
Exposure time per image $(\mathrm{s})$ & 0.040 \\
Space group & $P 2_{1}$ \\
$a, b, c(\AA)$ & $48.04,78.31,67.71$ \\
$\alpha, \beta, \gamma\left({ }^{\circ}\right)$ & $90,99.94,90$ \\
ISa & 12.0 \\
Resolution range $(\AA)$ & $18.6-1.35(1.39-1.35)$ \\
Total No. of reflections & $357812(26206)$ \\
No. of unique reflections & $107545(7947)$ \\
Completeness $(\%)$ & $99.4(99.6)$ \\
Multiplicity & $3.3(3.3)$ \\
$\langle I / \sigma(I)\rangle \dagger$ & $7.1(1.3)$ \\
$R_{\text {meas }}$ & $0.098(0.970)$ \\
Overall $B$ factor from Wilson plot $\left(\AA^{2}\right)$ & 15.2 \\
\hline
\end{tabular}

$\dagger$ Mean $I / \sigma(I)<2.0$ at $1.45 \AA$.

\subsection{Data collection and processing}

Crystals from several drops were briefly soaked in 22\%(w/v) PEG 3350, $0.2 M$ magnesium formate dihydrate before being flash-cooled in liquid nitrogen or were cooled directly from the crystallization drop in cases where the PEG 3350 concentration was $22 \%$. The best diffracting crystal grew in 22\% PEG 3350, $0.22 \mathrm{M}$ magnesium formate dehydrate, and data to $1.35 \AA$ resolution were collected on beamline I04 at Diamond Light Source (DLS), UK. A total of 1800 images were collected using $0.1^{\circ}$ oscillation width and the data were autoprocessed by xia2 (Winter, 2010), which makes use of $X D S$ (Kabsch, 2010) and the CCP4 suite (Winn et al., 2011) for integration and truncation of the data. The data-collection and processing statistics are listed in Table 3 .

\section{Results and discussion}

The SIP was purified to apparent purity $(>95 \%)$ by ionexchange chromatography as described in $\$ 2$. The purified protein appeared yellow and migrated as a single band at $\sim 30 \mathrm{kDa}$ on a $12 \%$ SDS-PAGE gel, as expected from theoretical calculations (Fig. 1a). Yellow-coloured crystals were dissolved and migrated as a $30 \mathrm{kDa}$ protein on an SDS-PAGE gel, as observed for the purified protein (Fig. 1a), and confirmed that the crystals consist of the SIP. The purified protein was also analysed by UV-visible spectroscopy and 
showed typical spectral features of an oxidized flavoprotein in the UV-visible region (Fig. 1b), with absorption peaks at 387 and $470 \mathrm{~nm}$.

The crystal which was used for data collection was multiple, similar to that shown in Fig. 2. However, it was possible to obtain good-quality diffraction data from one of the singlecrystal components, and no special precautions were needed in processing despite the apparent split crystal. No colour change of the crystal was observed during data collection, indicating an unchanged redox state of the FAD throughout $\mathrm{X}$-ray exposure.

The 22\% PEG 3350 concentration was sufficient to provide adequate crystal cryoprotection. In the partial diffraction image shown in Fig. 2, the lack of ice rings can be appreciated; although a weak diffuse scattering ring from the solvent is present, the maximum number of counts per pixel is not greater than 3 .

The SIP crystals belonged to the monoclinic space group $P 2_{1}$, with unit-cell parameters $a=48.04, b=78.31, c=67.71 \AA$, $\beta=99.94^{\circ}$. Cell-volume considerations (Matthews, 1968; Kantardjieff \& Rupp, 2003) indicate that there are two SIP monomers in the asymmetric unit, with a $V_{\mathrm{M}}$ of $2.13 \AA^{3} \mathrm{Da}^{-1}$ and an estimated solvent content of $42.4 \%$. Although a self-

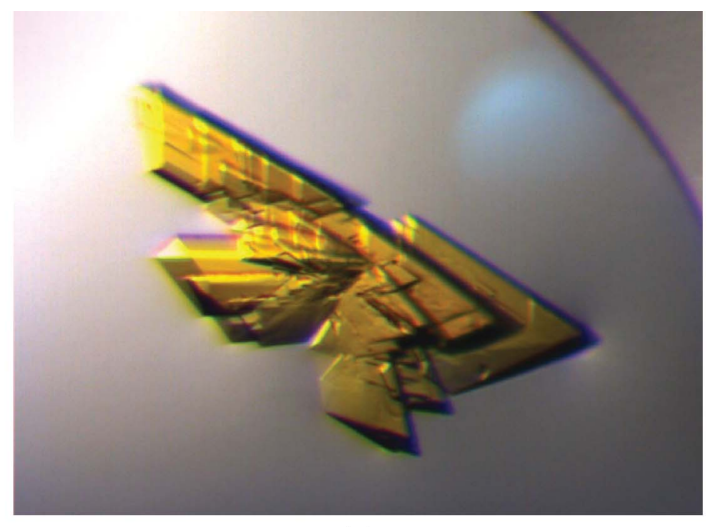

(a)

3.16

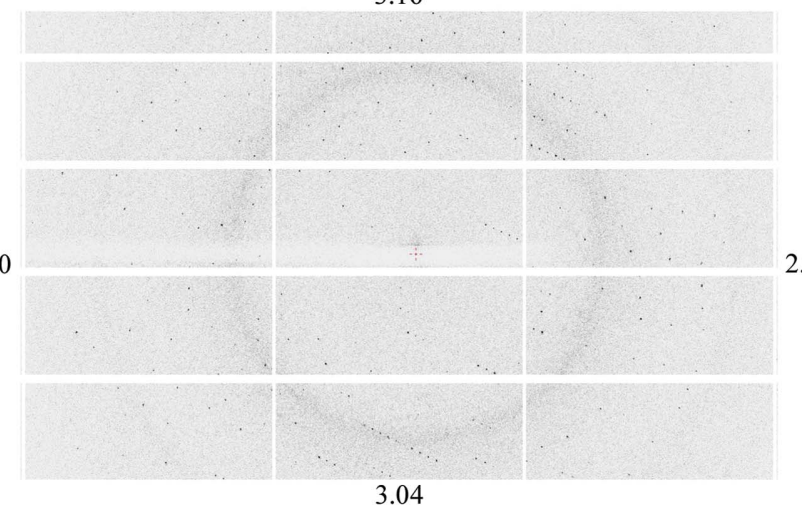

(b)

Figure 2

(a) Example of a multiple crystal of the SIP similar to that used for data collection on beamline I04 at DLS. (b) Detailed view of a SIP diffraction image obtained using a Pilatus 6M-F detector on beamline I04 at DLS. The numbers at the edge indicate the corresponding resolution limits. In the faintly visible diffuse scattering ring at $\sim 3.8 \AA$ resolution, the maximum number of counts per pixel away from Bragg reflections is 3 .

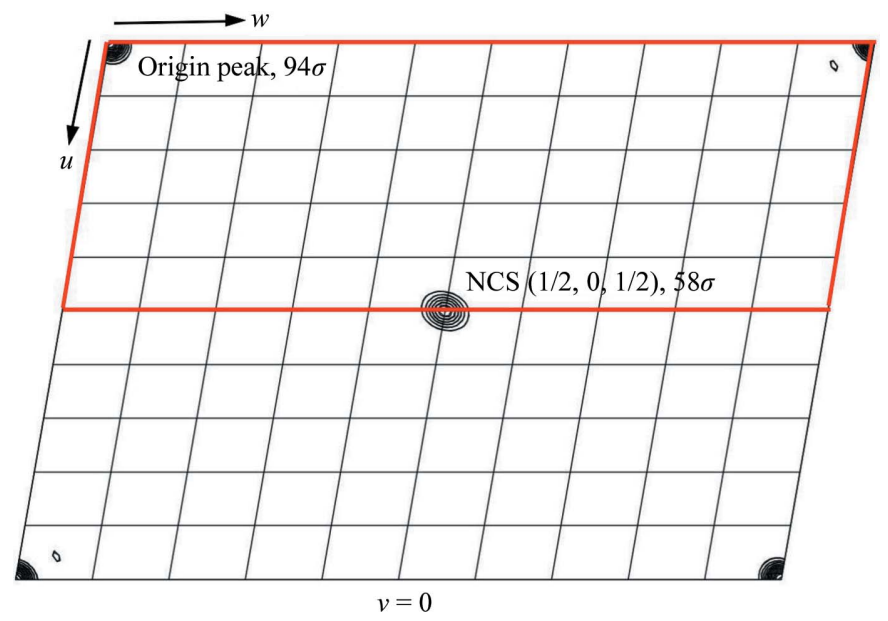

Figure 3

$v=0$ section of a native Patterson map calculated using data to $2.5 \AA$ resolution showing the presence of a strong non-origin peak at coordinates $(1 / 2,0,1 / 2)$ consistent with pseudo- $B$-centring. Contour levels are drawn every 10 map r.m.s.d. units between 5 and 100 r.m.s.d. units. The section is drawn between $0 \leq u \leq 1$ and $0 \leq w \leq 1$ and the asymmetric unit is outlined in red.

rotation plot failed to reveal any significant trace of noncrystallographic twofold rotation axes, a native Patterson map calculated using data to $2.5 \AA$ resolution displayed a strong non-origin peak at coordinates $(1 / 2,0,1 / 2)$ with a peak height $61 \%$ of that of the origin, suggesting translational noncrystallographic symmetry consistent with a pseudo- $B$-centred lattice (Fig. 3). The overall twinning score was 2.28; thus, the data do not appear to be twinned.

Attempts will be made to determine the crystal structure by molecular replacement (MR) using the previously determined SIP structures PDB entries 2gpj (2.2 А resolution) and 4yhb (1.89 ̊ resolution), which show 32 and $28 \%$ sequence identity, respectively, as templates. The higher resolution crystal structure of the SIP from S. frigidimarina will provide crucial information regarding the molecular mechanism underlying iron acquisition in microorganisms.

\section{Acknowledgements}

This work was financially supported by Project LISBOA-010145-FEDER-007660 (Microbiologia Molecular, Estrutural e Celular) funded by FEDER funds through COMPETE2020 Programa Operacional Competitividade e Internacionalização [POCI, the European Community's Seventh Framework Program (FP7/2007-2013)] under Grant Agreement 283570 (BioStruct-X), and by national funds and postdoctoral fellowships SFRH/BPD/94050/2013 and SFRH/BPD/93164/ 2013 to EM and BFM, respectively, through FCT (Fundação para a Ciência e a Tecnologia). Beamtime at I04 at Diamond Light Source (DLS) and assistance from the beamline staff are gratefully acknowledged (http://www.diamond.ac.uk/ Beamlines/Mx/I04.html).

\section{References}

Blommel, P. G., Becker, K. J., Duvnjak, P. \& Fox, B. G. (2007). Biotechnol. Prog. 23, 585-598. 
Brickman, T. J. \& McIntosh, M. A. (1992). J. Biol. Chem. 267, 1235012355.

Butterton, J. R. \& Calderwood, S. B. (1994). J. Bacteriol. 176, 56315638.

Crosa, J. H. \& Walsh, C. T. (2002). Microbiol. Mol. Biol. Rev. 66, 223-249.

Deneer, H. G., Healey, V. \& Boychuk, I. (1995). Microbiology, 141, 1985-1992.

Holland, H. D. (2006). Philos. Trans. R. Soc. Lond. B Biol. Sci. 361, 903-915.

Kabsch, W. (2010). Acta Cryst. D66, 125-132.

Kantardjieff, K. A. \& Rupp, B. (2003). Protein Sci. 12, 1865-1871.

Li, K., Chen, W.-H. \& Bruner, S. D. (2015). Biochemistry, 54, 39894000.

Matthews, B. W. (1968). J. Mol. Biol. 33, 491-497.
Miethke, M., Hou, J. \& Marahiel, M. A. (2011). Biochemistry, 50, 10951-10964.

Miethke, M. \& Marahiel, M. A. (2007). Microbiol. Mol. Biol. Rev. 71, 413-451.

Neilands, J. B. (1981). Annu. Rev. Biochem. 50, 715-731.

Ryndak, M. B., Wang, S., Smith, I. \& Rodriguez, G. M. (2010). J. Bacteriol. 192, 861-869.

Saha, M., Sarkar, S., Sarkar, B., Sharma, B. K., Bhattacharjee, S. \& Tribedi, P. (2016). Environ. Sci. Pollut. Res. Int. 23, 3984-3999.

Schalk, I. J. \& Guillon, L. (2013). Amino Acids, 44, 1267-1277.

Studier, F. W. (2005). Protein Expr. Purif. 41, 207-234.

Wandersman, C. \& Delepelaire, P. (2004). Annu. Rev. Microbiol. 58, 611-647.

Winn, M. D. et al. (2011). Acta Cryst. D67, 235-242.

Winter, G. (2010). J. Appl. Cryst. 43, 186-190. 